\title{
Upper GIS Endoscopy Indications of Patients Consulted at Internal Medicine Outpatient Clinics and Data Obtained According to These Indications
}

\author{
Muhammed Tunc, Banu Boyuk, Osman Mavis \\ Department of Internal Medicine, Gaziosmanpasa Taksim Education and Research Hospital, Istanbul, Turkey \\ Email:drmta@hotmail.com
}

Received 17 March 2016; accepted 19 April 2016; published 22 April 2016

Copyright (C) 2016 by authors and Scientific Research Publishing Inc. This work is licensed under the Creative Commons Attribution International License (CC BY). http://creativecommons.org/licenses/by/4.0/

(c) (i) Open Access

\section{Abstract}

Background and aim: Esophagogastroduodenoscopy is an innovative method used in order to diagnose esophagus, stomach, and duodenum diseases. Esophagogastroduodenoscopy is fundamental for the prognosis of various benign and malign upper gastrointestinal diseases, as well as for therapy or disease follow-up. The aim of the present study is to classify endoscopy results according to indications and to reveal which indications and results are most commonly seen. Materials and methods: The Esophagogastroduodenoscopy results of 6243 patients were evaluated retrospectively; all patients had applied to the Gaziosmanpaşa Taksim Education and Research Hospital Department of Internal Medicine from 2010 to 2015 on either an outpatient or inpatient basis. Results: In our study, 2548 of the patients were male and 3695 were female. The mean age of the patients was $49.37 \pm 16.90$ years. The indications for Esophagogastroduodenoscopy were dyspeptic symptoms for $\mathbf{7 2 . 8 \%}$ of females and $\mathbf{7 0 . 4 \%}$ of males. Anemia was the indication for $12.1 \%$ of females and $11.8 \%$ of males. Other indications included gastrointestinal bleeding, dysphagia, nausea and vomiting, gastroesophageal reflux disease symptoms and weight loss. Peptic ulcer disease was the result of Esophagogastroduodenoscopy for $55.7 \%$ of females and $50.6 \%$ of males. Gastric ulcer (15.2\% of females and $16 \%$ of males), reflux esophagitis $(8.1 \%$ of females and $10.1 \%$ of males), and duodenal ulcer (6.8\% of females and $10.1 \%$ of males) were the other results. Malignancy was mostly observed in patients whose indications were anemia. Conclusion: The upper gastrointestinal system endoscopy continues to be an up-to-date method of displaying the effectiveness of diseases to assist in the diagnosis and treatment of the symptoms and complaints of the gastrointestinal system, particularly in the evaluation of patients having persistent symptoms. 


\section{Keywords}

\section{Endoscopy, Indications, Results}

\section{Introduction}

Peptic ulcer disease (PUD), gastroesophageal reflux disease (GERD), and cancers are three of the most common healthcare topics worldwide [1]-[4]. The most common symptoms of these conditions are vomiting, nausea, heartburn, epigastric pain, retrosternal pain, and dysphagia. At present, the most popular technique for screening the interior surfaces of the gastrointestinal system (GIS) is endoscopy [5]. Currently, Esophagogastroduodenoscopy (EGD) is the technology used for standardized endoscopic imaging in order to diagnose the diseases of the esophagus, stomach, and duodenum in daily medical practice. Even though the upper GIS endoscopy is a practical method for diagnosis, therapy, and follow-up, the complications of performing upper GI endoscopy can cause negative effects such as perforation, hemorrhage, cardiac arrhythmia, aspiration, and even a MalloryWeiss tear [6]. In 1988, the American Society for Gastrointestinal Endoscopy (ASGE) published codes to assist in the examination of the relationship between EGD accuracy and relevant endoscopic results [7]. However, the references for ordering an EGD can vary according to the population as they are created under particular circumstances of referral and epidemiological patterns of disease. Information on histological diagnosis is not available because of inadequacy of the records. Although biopsies are routinely taken from lesions, some patients don't accept to use them or some patients don't give them for pathological examination. As a result of these, our data about histological examination is inadequate.

The aim of the present study is to classify endoscopy results according to indications and to reveal which indications and results are most commonly seen. Thus we want to underline which symptoms or indications require the performance of upper GI endoscopy more than other symptoms or indications, especially to reveal which indications can strongly suggest malignancies.

\section{Materials and Methods}

A retrospective study was performed at the GOP Taksim Education and Research Hospital Department of Internal Medicine from 2010 to 2015 on either an outpatient or an inpatient basis. GOP Taksim Education and research hospital is one of the biggest hospitals of Turkey. The number of admission to our inpatient and outpatient clinic per year is about 50.000 patients. The inclusion criteria were all patients undergoing upper GI endoscopy between 2010-2015 in our internal medicine unit. All endoscopy procedures were performed by same endoscopist and we used the data which this endoscopist recorded personally. We also matched them with hospital data. By this way, we made sure about the number of patients and results. It included 6243 patients. All patients underwent standard pre-procedure preparation that included an overnight fast; however, nasogastric drainage of the stomach was preferred for those with suspected gastric outlet obstruction. The main forms of analgesia and sedation used were throat spray with $2 \%$ lidocaine (Xylocaine ${ }^{\circledR}$, AstraZeneca UK Limited, Luton, UK) and intravenous sedation with midazolam (Dormicum ${ }^{\circledR}$, Roche, Switzerland), respectively. Data extracted from the records included the age and gender of the patients, principal indication for the procedure, and primary upper gastrointestinal endoscopy (UGIE) findings. Although biopsies were routinely taken from lesions in the stomach and esophagus for histology, information on histological diagnosis was not available because of inadequacy of the records. The study protocol was approved by the GOP Taksim Research and Education Hospital Ethics Committee, Istanbul, Turkey. This research received no specific grant from any funding agency in the public, commercial or not-for profit sectors. Competing interest: none to declare.

Descriptive statistics were expressed as mean and standard deviation; minimum and maximum for numerical variables; and as number and percentage for categorical variables, where appropriate.

\section{Results}

Table 1 summarizes the characteristics of the study population. A total of 6243 patients underwent a complete UGIE over the period. 3695 (59.2\%) of the patients were female; 1271 patients (20.4\%) were in the 41 - 50 year 
Table 1. Patient demographics.

\begin{tabular}{ccc}
\hline & \multicolumn{2}{c}{ Patient group $(\boldsymbol{n}=\mathbf{6 2 4 3})$} \\
\cline { 2 - 3 } Male Gender & \multicolumn{2}{c}{ Mean \pm SD/n, \% } \\
Female & 3695 & 40.8 \\
Age (years) & 49.37 & 59.2 \\
$10-20$ & 171 & \pm 16.90 \\
$21-30$ & 799 & 2.7 \\
$31-40$ & 1109 & 12.8 \\
$41-50$ & 1271 & 17.8 \\
$51-60$ & 1197 & 20.4 \\
$61-70$ & 898 & 19.2 \\
$71-80$ & 608 & 14.4 \\
$81-90$ & 172 & 9.7 \\
$91-100$ & 18 & 2.8 \\
\hline
\end{tabular}

old age range; and 190 patients (3.1\%) were over 81 years old. By far the most common primary indication for UGIE was dyspepsia occurring without any other symptoms, accounting for almost 2691 (72.8\%) of females and 1794 (70.4\%) of males. For 446 (12.1\%) of the female patients and 301 (11.8\%) of the male patients, the primary indication was anemia. Other notable primary indications were recurrent vomiting, dyspepsia associated with weight loss, GERD symptoms, and upper gastrointestinal (UGI) bleeding (Table 2). Endoscopic findings are presented in Table 3.

Half of the patients had peptic ulcer disease, and this was the most common finding. PUD, defined as gastritis, duodenitis, or both, was the most common positive finding. This was seen in 2061 (55.7\%) of all female patients and 1293 (50.6\%) of all male patients. Gastric ulcer (569 female patients accounting 15.2\% of all females, 407 male patients accounting $16.0 \%$ of all males) was seen more frequently than duodenal ulcer (287 female patients accounting $6.8 \%$ of females, 245 male patients accounting $9.5 \%$ of males). Gastric cancer was found in 51 (1.4\%) of female cases and in 45 (1.7\%) of male cases. Duodenal cancer was found in just two female cases, and there was no duodenal cancer in the male patient group. Non-candida esophagitis was found in 304 (8.1\%) of female patients and in 266 (10.3\%) of male patients. Normal endoscopic findings were seen very rarely (39 female patients accounting $1.0 \%$ of all female patients, 19 males patients accounting $0.7 \%$ of all male patients). Mallory-Weiss syndrome (MWS) was seen in just one male patient. Other less commonly reported findings were esophageal varices, gastric polyps, and distal esophageal cancer. Table 4 summarizes the endoscopic findings according to primary indication for UGIE. For all primary indications, the most common result was peptic ulcer disease. Normal endoscopic findings were most commonly seen with an anemia indication.

Reflux esophagitis was most commonly seen with a dyspepsia indication. Esophageal varices were most commonly seen with anemia and upper GIS bleeding indications. Esophageal cancer was most commonly seen with a dysphagia indication, and gastric cancer was most commonly seen with an anemia indication.

\section{Discussion}

This study retrospectively investigated the endoscopy results according to indications in a sample of the Turkish population. We found the most common primary indication for UGIE was dyspepsia occurring without any other symptoms and accounting for almost $72.8 \%$ of females and $70.4 \%$ of males, a finding which is in agreement with other published findings. As in our study, Ayuo et al. found the most common primary indication for UGIE in Kenya was dyspepsia [8]. Taye et al. [9], in a review of 10,000 endoscopies in Ethiopia between 1979 and 1994, showed that 59.4\% were referred because of dyspepsia, whereas it was shown that in Nigeria in 2009, 61\% of patients undergoing endoscopy had dyspepsia [10]. Generally, our findings are consistent with the concept that dyspepsia is a marker for various upper gastrointestinal pathologies that can only be differentiated by upper 
Table 2. Primary indications for UGIE.

\begin{tabular}{ccccc}
\hline \multirow{2}{*}{ INDICATION } & \multicolumn{2}{c}{ GENDER } & \multicolumn{2}{c}{ MALE (n/\%) } \\
\cline { 2 - 5 } FEMALE (n/\%) & 1794 & $70.4 \%$ \\
\hline Dyspeptic symptoms & 2691 & $72.8 \%$ & 85 & $3.3 \%$ \\
Dyspepsia \& weightloss & 92 & $2.5 \%$ & 84 & $3.3 \%$ \\
GERD symptoms & 71 & $1.9 \%$ & 47 & $1.8 \%$ \\
Dysphagia & 76 & $2.1 \%$ & 26 & $1.0 \%$ \\
Nausea-vomiting & 74 & $2.0 \%$ & 212 & $8.3 \%$ \\
Upper GI bleeding & 244 & $6.6 \%$ & 301 & $11.8 \%$ \\
Anemia & 446 & $12.1 \%$ & & \\
\hline
\end{tabular}

Table 3. Primary upper GI endoscopic findings.

\begin{tabular}{|c|c|c|c|c|}
\hline \multirow{3}{*}{$\begin{array}{c}\text { ENDOSCOPICFINDINGS } \\
\text { Normal findings }\end{array}$} & \multicolumn{2}{|c|}{ GENDER } & & \\
\hline & \multicolumn{2}{|c|}{ FEMALE $\boldsymbol{n}, \%$} & \multicolumn{2}{|c|}{ MALE $n, \%$} \\
\hline & 39 & $1.0 \%$ & 19 & $0.7 \%$ \\
\hline Reflux esophagitis & 304 & $8.1 \%$ & 266 & $10.3 \%$ \\
\hline Esophagealcandidiasis & 3 & $0.1 \%$ & 0 & $0.0 \%$ \\
\hline Esophagealvarices & 20 & $0.5 \%$ & 33 & $1.3 \%$ \\
\hline Hiatushernia & 232 & $6.2 \%$ & 166 & $6.4 \%$ \\
\hline Esophagealcancer & 8 & $0.2 \%$ & 4 & $0.2 \%$ \\
\hline Mallory-Weiss & 0 & $0.0 \%$ & 1 & $0.0 \%$ \\
\hline Pepticulcerdisease & 2061 & $55.7 \%$ & 1,293 & $50.6 \%$ \\
\hline Gastriculcer & 569 & $15.2 \%$ & 407 & $16.0 \%$ \\
\hline Gastricpolyp & 65 & $1.7 \%$ & 39 & $1.4 \%$ \\
\hline Pyloricstenosis & 6 & $2.0 \%$ & 2 & $1.0 \%$ \\
\hline Gastriccancer & 51 & $1.4 \%$ & 45 & $1.7 \%$ \\
\hline Gastricvarices & 2 & $0.1 \%$ & 2 & $0.1 \%$ \\
\hline Duodenalulcer & 287 & $6.8 \%$ & 245 & $9.5 \%$ \\
\hline Duodenaldiverticulum & 35 & $0.9 \%$ & 22 & $0.8 \%$ \\
\hline Duodenalcancer & 2 & $0.1 \%$ & 0 & $0.0 \%$ \\
\hline
\end{tabular}

gastrointestinal endoscopy among other sophisticated and expensive tests. For $12.1 \%$ of the female patients and $11.8 \%$ of the male patients, the primary indication was anemia, which was the second most common indication. Unlike our study, many other published studies found dysphagia as the second most common indication. Ayuo et al. [8] found dysphagia to be the second most frequent indication for endoscopy, though distantly so, accounting for $13.3 \%$. Other notable primary indications were recurrent vomiting, dyspepsia associated with weight loss, GERD symptoms, and UGI bleeding. The most common finding was PUD, defined as gastritis, duodenitis, or both. Half of the patients had PUD, and it was also the most common positive finding (55.7\% of female patients, $50.6 \%$ of male patients). Unlike in our study, O. Ayuo et al. [8] determined normal findings in the majority (30.4\%) of the patients. The study conducted by Loffeld et al. revealed that the prevalence of the gastritis incidence was 5.9\% [11], and the prevalence stated in the study performed by Galban et al. [12] in Cuba was $91.6 \%$. In the study of Galban et al. [12], erosive duodenitis (bulbitis) was found in 63.5\% of male patients, in $54.4 \%$ of female patients, and in $57.8 \%$ in the total number of patients [11]. Gastric ulcer (15.2\% of female patients, $16.0 \%$ of male patients) was seen more frequently than duodenal ulcer (6.8\% of female patients, $9.5 \%$ 
Table 4. Endoscopic findings according to primary indications for UGIE.

\begin{tabular}{|c|c|c|c|c|c|c|c|}
\hline Indication (n/\%) & $\begin{array}{l}\text { Dyspeptic } \\
\text { symptoms }\end{array}$ & $\begin{array}{c}\text { Dyspepsia \& } \\
\text { weight loss }\end{array}$ & $\begin{array}{c}\text { GERD } \\
\text { symptoms }\end{array}$ & Dysphagia & Nausea-vomiting & $\begin{array}{l}\text { Upper GI } \\
\text { bleeding }\end{array}$ & Anemia \\
\hline Normal findings & 19 (0.38\%) & $4(2 \%)$ & $4(1.7 \%)$ & $1(0.9 \%)$ & $1(0.8 \%)$ & $9(1.6 \%)$ & $22(2.6 \%)$ \\
\hline $\begin{array}{c}\text { Reflux } \\
\text { esophagitis }\end{array}$ & $555(11.3 \%)$ & $19(9.6 \%)$ & $131(56.7 \%)$ & 17 (13.9\%) & $10(8.7 \%)$ & $44(7.6 \%)$ & $55(6.4 \%)$ \\
\hline Esophagealvarices & $12(0.24 \%)$ & $1(0.51 \%)$ & $2(0.8 \%)$ & $2(1.6 \%)$ & 0 & $26(4.5 \%)$ & $30(3.5 \%)$ \\
\hline Hiatushernia & 368 (7.5\%) & $10(5.1 \%)$ & $31(13.4 \%)$ & $11(8.9 \%)$ & 15 (13.1\%) & $35(6.2 \%)$ & $76(8.9 \%)$ \\
\hline Pepticulcerdisease & 2699 (55.2\%) & 84 (42.9\%) & $20(8.6 \%)$ & $60(48.8 \%)$ & $50(43.6 \%)$ & $84(14.8 \%)$ & $366(43.1 \%)$ \\
\hline Gastriculcer & 659 (13.9\%) & 36 (18.4\%) & $25(10.8 \%)$ & $14(11.4 \%)$ & 24 (20.9\%) & $176(31 \%)$ & 164 (19.3\%) \\
\hline Gastricpolyp & $79(1.6 \%)$ & $3(1.5 \%)$ & $1(0.43 \%)$ & $3(2.4 \%)$ & $2(1.6 \%)$ & $8(1.4 \%)$ & $33(3.9 \%)$ \\
\hline Gastriccancer & $23(0.47 \%)$ & $21(10.8 \%)$ & 0 & $5(4 \%)$ & $2(1.6 \%)$ & $21(3.7 \%)$ & $26(3 \%)$ \\
\hline Duodenalulcer & $420(8.6 \%)$ & 17 (8.6\%) & $17(7.6 \%)$ & $8(6.5 \%)$ & $10(8.9 \%)$ & 157 (27.6\%) & 67 (7.9\%) \\
\hline Duodenaldiverticulum & 49 (0.91\%) & $1(0.5 \%)$ & 0 & $2(1.6 \%)$ & $1(0.8 \%)$ & $7(1.6 \%)$ & $9(1.4 \%)$ \\
\hline
\end{tabular}

of male patients). Unlike in our study, many studies found duodenal ulcer more frequently. The studies performed in Holland [11] and Cuba [12] revealed that the prevalences of gastric ulcer were $1.8 \%$ and $6.2 \%$ and of duodenal ulcer were $2.1 \%$ and $15.8 \%$, respectively. Gastric cancer was found in $1.4 \%$ of female cases and in $1.8 \%$ of male cases. Duodenal cancer was found in just two female cases. There was no duodenal cancer in the male patient group. Syam et al. [13] found gastric and duodenal cancer equally (15.4\%). They found GIS cancer more frequently. This result can be caused by feeding habits. Esophageal cancer was most commonly seen with a dysphagia indication and gastric cancer was most commonly seen with an anemia indication. According to these results, anemia and dysphagia, together or separately, can be cancer symptoms. Physicians must pay attention to these symptoms independent of patient age. Non-candida esophagitis was found in $8.1 \%$ of female patients and $10.3 \%$ of male patients. A study performed retrospectively by Loffeld et al.

[11] from January 1992 to December 2011 revealed that 16\% of 29,218 patients had esophagitis. A research study conducted from 1993 to 1994 in Finland stated that the prevalence of esophagitis was $12 \%$ in the 15 - 44 year old patient group and $15 \%$ in the over 45 year old patient group [10]. Endoscopic research performed on 3556 patients in Cuba by Galban et al. from May to November of 2007 revealed that esophagitis was observed in $25.2 \%$ of the participants [14]. Normal endoscopic findings were seen very rarely $(1.0 \%$ of female patients, $0.7 \%$ of male patients). Unlike in our study, O. Ayuo et al. [8] had normal findings in the majority (30.4\%) of the patients. Actually, this is surprising because in our country the majority of patients with dyspeptic symptoms have pathology. This result can be caused by feeding habits and unconscious drug usage. It also can be caused by low socio-economic status of patients living around our hospital. As a result of this, upper GIS endoscopy should be performed on patients who have persistent dyspeptic or other GIS symptoms. For all primary indications, the most common result is peptic ulcer disease. Normal endoscopic findings are most commonly seen with an anemia indication. Reflux esophagitis is most commonly seen with a dyspepsia indication. Esophageal varices are most commonly seen with anemia and upper GIS bleeding indications. Esophageal cancer is most commonly seen with dysphagia indication, and gastric cancer is most commonly seen with an anemia indication.

\section{Conclusion}

As a result of our findings, we conclude that the upper gastrointestinal system endoscopy continues to be an up-to-date method of displaying the effectiveness of diseases to assist in the diagnosis and treatment of the symptoms and complaints of the gastrointestinal system, particularly in the evaluation of the patients having persistent symptoms. Anemia and dysphagia can be alarm symptoms for malignancies. Performing upper GI endoscopy is cheap and relatively safe. Patients having persistent dyspeptic symptoms, anemia, dysphagia, or weight lost, should have this procedure performed.

\section{References}

[1] Williams, J.G., Roberts, S.E., Ali, M.F., Cheung, W.Y., Cohen, D.R., et al. (2007) Gastroenterology Services in the 
UK. The Burden of Disease, and the Organization and Delivery of Services for Gastrointestinal and Liver Disorders: A Review of the Evidence. Gut, 56, 1-113. http://dx.doi.org/10.1136/gut.2006.117598

[2] Merletti, F., Galassi, C. and Spadea, T. (2011) The Socioeconomic Determinants of Cancer. Environ Health, 10 , S7. http://dx.doi.org/10.1186/1476-069X-10-S1-S7

[3] Kim, E.Y., Choi, I.J., Kwon, K.A., Ryu, J.K., Dong, S.H., et al. (2014) Highlights from the 50th Seminar of the Korean Society of Gastrointestinal Endoscopy. Clinical Endoscopy, 47, 285-294. http://dx.doi.org/10.5946/ce.2014.47.4.285

[4] Kwon, K.A., Choi, I.J., Kim, E.Y., Dong, S.H. and Hahm, K.B. (2013) Highlights of the 48th Seminar of the Korean Society of Gastrointestinal Endoscopy. Clinical Endoscopy, 46, 203-211. http://dx.doi.org/10.5946/ce.2013.46.3.203

[5] Choi, K.S. and Suh, M. (2014) Screening for Gastric Cancer: The Usefulness of Endoscopy. Clinical Endoscopy, 47, 490-496. http://dx.doi.org/10.5946/ce.2014.47.6.490

[6] Ginzburg, L., Greenwald, D. and Cohen, J. (2007) Complications of Endoscopy. Gastrointestinal Endoscopy Clinics of North America, 17, 405-432. http://dx.doi.org/10.1016/j.giec.2007.03.009

[7] American Society for Gastrointestinal Endoscopy (2000) Appropriate Use of Gastrointestinal Endoscopy. Gastrointestinal Endoscopy, 52, 831-837. http://dx.doi.org/10.1016/S0016-5107(00)70219-7

[8] Ayuo, P.O., Some, F.F. and Kiplagat, J. (2014) Upper Gastrointestinal Endoscopy Findings in Patients Referred with Upper Gastrointestinal Symptomsin Eldoret, Kenya: A Retrospective Review. East African Medical Journal, 91, $267-$ 273.

[9] Taye, M., Kassa, E., Mengesha, B., Gemechu, T. and Tsega, E. (2004) Upper Gastrointestinal Endoscopy: A Review of 10,000 Cases. Ethiopian Medical Journal, 42, 97-107.

[10] Olokoba, A.B., Olokoba, L.B., Jimoh, A.A., Salawu, F.K., Danburam, A. and Ehalaiye, B.F. (2009) Upper Gastrointestinal Tract Endoscopy Indications in Northern Nigeria. Journal of the College of Physicians and Surgeons Pakistan, 19, 327-328.

[11] Loffeld, R.J., Liberov, B. and Dekkers, P.E. (2013) The Changing Prevalence of Upper Gastrointestinal Endoscopic Diagnoses: A Single-Centre Study. Netherlands Journal of Medicine, 70, 222-226.

[12] Galban, E., Arus, E. and Periles, U. (2012) Endoscopic Findings and Associated Risk Factors in Primary Health Care Settings in Havana, Cuba. MEDICC Review, 14, 30-37.

[13] Syam, A.F., Abdullah, M., Makmun, D., Simadibrata, M., Djojoningrat, D., Manan, C., Rani, A.A. and Daldiyono, D. (2005) The Causes of Upper Gastrointestinal Bleeding in the National Referral Hospital: Evaluation on Upper Gastrointestinal Tract Endoscopic Result in Five Years Period. The Indonesian Journal of Gastroenterology, Hepatology, and Digestive Endoscopy, 6, 71-74.

[14] Heikkinen, M.T., Pikkarainen, P.H., Takala, J.T., et al. (1997) Diagnostic Methods in Dyspepsia: The Usefulness of Upper Abdominal Ultrasound and Gastroscopy. Scand J Prim Health Care, 15, 82-86. http://dx.doi.org/10.3109/02813439709018492 